\section{AUTOAPRESENTAÇÃO CORPORAL DE LUTADORAS DE ARTES MARCIAIS MISTAS (MMA) NO INSTAGRAM}

\author{
BODILY SELF-PRESENTATION OF FEMALE MIXED MARTIAL ARTS \\ (MMA) FIGHTERS ON INSTAGRAM C己
}

\section{AUTOPRESENTACIÓN CORPORAL DE LUCHADORAS DE ARTES MARCIALES MIXTAS (MMA) EN INSTAGRAM C?}

d0) https://doi.org/10.22456/1982-8918.105338

João Paulo Silva de Oliveira* <joaopaulo.tdf@gmail.com>

Christiane Garcia Macedo** <christiane.macedo@univasf.edu.br>

Alvaro Rego Millen Neto** <alvaro.millen@univasf.edu.br>

\footnotetext{
*Instituto Federal de Educação, Ciência e Tecnologia da Bahia. Juazeiro, BA, Brasil. Brasil.

${ }^{* *}$ Universidade Federal do Vale do São Francisco. Petrolina, PE, Brasil.
}

Resumo: Objetivamos analisar a autoapresentação corporal de lutadoras de MMA no Instagram. Foram analisadas imagens postadas por lutadoras campeãs do Ultimate Fighting Championship (UFC), considerando a representação midiática da imagem da mulher atleta, a objetificação e a hipersexualização de seus corpos. Para tal, utilizamos um esquema de codificação com categorias para análise de imagens baseado nos estudos de Goffman. Verificamos que o Instagram foi utilizado com a finalidade típica das redes sociais (compartilhamento de informações pessoais e interação social), mas a marca do UFC aparece com frequência nas imagens postadas por todas as lutadoras. Em geral, as imagens analisadas não apresentam a tendência, persistente na cobertura da mídia esportiva, de sexualização do corpo das mulheres atletas. As imagens que remetem a essa representação foram observadas nos contextos específicos que envolvem a organização UFC. As imagens analisadas mostram uma feminilidade plural.

Palavras chave: Esportes de Combate. Estudos de Gênero. Rede social.
Recebido em: 13 jul. 2020 Aprovado em: 31 jan. 2021 Publicado em: 02 abr. 2021

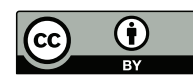

Este é um artigo publicado sob a licença Creative Commons Atribuição 4.0 Internacional (CC BY 4.0).

eISSN: $1982-8918$ 


\section{INTRODUÇÃO}

As Artes Marciais Mistas (MMA - do inglês Mixed Martial Arts) podem ser caracterizadas como um esporte de combate cujas regras permitem e incentivam a mistura de técnicas de lutas provenientes de diferentes estilos, tais como o jiu-jítsu, o wrestling, o boxe, o muay thai, o kick boxing, dentre outras. Especialmente na última década, o MMA tem se inserido massiva e globalmente como um elemento cultural capaz de agregar cada vez mais consumidores e adeptos. Os eventos da modalidade estão diretamente ligados à promoção de grandes espetáculos, que são altamente comercializáveis.

Essa característica comercial do MMA fica evidenciada nas estratégias de venda midiatizadas das organizações que o promovem. Exemplos dessas estratégias podem ser vistos no peculiar falatório que ocorre nos eventos de divulgação das lutas, o trash talk ${ }^{1}$; na promoção das money fights ${ }^{2}$; nas provocações dos atletas via redes sociais, envolvendo diferentes mercados (nacionalidades, etnias, religiões etc.); e, de modo mais específico, para as análises apresentadas neste artigo, nas formas de exposição corporal apresentadas nas lutas e em eventos relacionados, como a pesagem de atletas para checar se estão dentro dos limites das categorias. Essa exposição de corpos é recorrente para as atletas mulheres e também para os homens, mas há idiossincrasias que precisam ser compreendidas, a começar pela tradicional participação de mulheres como ring girls ${ }^{3}$ - aliás, essa é a primeira forma de participação feminina no show do MMA.

No que se refere à participação das mulheres enquanto lutadoras, o MMA apresenta uma trajetória histórica semelhante à maioria das modalidades profundamente masculinizadoras, que são atravessadas por relações de poder expressas de diferentes formas: nas desigualdades de acesso e permanência na modalidade; na menor quantidade de competições; e no menor espaço disponibilizado pelos diferentes artefatos midiáticos (GOELLNER; JAEGER; FIGUEIRA, 2010).

Além da pouca cobertura dos esportes femininos e das atletas nos diversos artefatos midiáticos, a análise do corpus de estudos nacionais e internacionais específicos mostra que a cobertura midiática esportiva retrata diferentemente mulheres atletas em relação aos homens. Na mídia esportiva digital e impressa, encontra-se um espaço generificado e generificador, que produz relações hierarquizadas entre gêneros (GOELLNER; SILVA; BOTELHO-GOMES, 2013; MÜHLLEN; GOELLNER, 2012). A cobertura midiática de homens atletas é focada em suas realizações atléticas; por outro lado, a cobertura da mídia esportiva sobre as mulheres atletas quase sempre se refere à atratividade, heterossexualidade e emotividade da atleta, além do papel de esposa e mãe (KNIJNIK; SOUZA, 2004). As imagens das atletas femininas tendem a ser destacadas quando em esportes que tradicionalmente

\footnotetext{
1 Trata-se de uma prática de provocações verbais usada para desequilibrar emocionalmente o adversário. No caso do MMA, assim como no boxe, é também uma forma de promover as lutas.

2 Lutas que são promovidas em função, prioritária e deliberadamente, do potencial para gerar lucro. Nessas lutas o critério para a definição dos competidores foge à lógica definida pelas formas de classificação (rankings) do esporte moderno. O que vale, nesses casos, é o apelo midiático para o consumo, não raro constituído a partir de trash talks. 3 Como são chamadas as mulheres que entram nos ringues entre os rounds de um combate, carregando uma placa que mostra o número do próximo round.
} 
são considerados como mais apropriados para o gênero, em poses paradas ou passivas em vez de ações atléticas, reforçando, de certa maneira, os papéis de gênero estereotipados (DADDARIO, 1994; DUNCAN, 1990; HARDIN et al., 2002; MESSNER, 1988). A cobertura fotográfica apresenta uma tendência de fotografias sexualizadas de atletas femininas em revistas, jornais e sites especializados em esportes (KIM; SAGAS; WALKER, 2010; PEREIRA; PONTES; RIBEIRO, 2015; SHALLER, 2006).

Muitos estudos contemporâneos sobre gênero e sexualização do corpo da mulher na cultura popular e no contexto esportivo tomam como ponto de partida o trabalho de Goffman (1988). Destacamos o estudo de Hatton e Trautner (2011), que utilizou uma estrutura analítica para verificar o quanto uma imagem era sexualizada ou hipersexualizada. Esses autores compararam imagens de mulheres e homens nas capas da revista Rolling Stone - 1967 a 2009 - e concluíram que as imagens tanto das mulheres quanto dos homens são mais sexualizadas ao longo do tempo, mas a descoberta mais notável foi a mudança em como as mulheres passaram a ser hipersexualizadas. No contexto esportivo, destacamos os trabalhos de Kim e Sagas (2014) e Smith e Sanderson (2015). Os primeiros usaram uma versão modificada de Goffman (1988) para comparar as imagens de atletas e modelos de moda femininos; seus resultados revelaram pouca diferença entre os grupos no que diz respeito à sexualização das imagens. Na pesquisa de Smith e Sanderson (2015), o objetivo foi examinar e comparar a autoapresentação de atletas olímpicos (mulheres e homens). Os resultados indicaram diferenças no uso das mídias sociais entre mulheres e homens atletas.

Aparticipação de lutadoras do sexo feminino no Ultimate Fighting Championship ${ }^{4}$ (UFC) é relativamente recente. O primeiro evento da franquia ocorreu em 1993, já a participação de mulheres atletas só foi ocorrer 20 anos depois, em 2013. Como se trata de uma modalidade que socialmente reforça as ideias de masculinidade hegemônica, a inserção das lutadoras no UFC implicou demandas extraesportivas para essas mulheres. Para serem valorizadas nas grandes empresas de MMA, as lutadoras precisam conviver com a ambivalência de serem fortes, competitivas e não se distanciarem de uma representação conservadora e, em certa medida, erotizada, do que é ser mulher (MILLEN NETO; GARCIA; VOTRE, 2016).

A maioria dos trabalhos de pesquisa encontrada tem como preocupação a investigação de como as mulheres atletas são retratadas nas diversas mídias de massa. No entanto, é cada vez mais crescente o número de atletas de diversas modalidades que usam as mídias sociais com diversas finalidades, seja interação com os fãs e/ou divulgação de suas marcas. Na atualidade, observa-se que as relações sociais medidas por plataformas comunicacionais em rede são cada vez mais intensas e hegemônicas na vida das pessoas (MISKOLCl, 2016) - inclusive de atletas de diferentes modalidades. Entre as diversas mídias sociais, o Instagram, com 1 bilhão de usuários ativos por mês ${ }^{5}$, destaca-se como a principal rede social

\footnotetext{
4 O UFC é, atualmente, a maior promotora de eventos de MMA do mundo, tanto para as categorias femininas quanto para as masculinas. Suas lutas transmitidas em 30 idiomas para mais de 149 países.

5 Informação disponível na matéria "Instagram faz 10 anos como uma das maiores redes sociais do mundo e de olho no TikTok, para não envelhecer", disponível em: https://g1.globo.com/economia/tecnologia/noticia/2020/10/06/ instagram-faz-10-anos-como-uma-das-maiores-redes-sociais-do-mundo-e-de-olho-no-tiktok-para-nao-envelhecer. ghtml. Acesso em: 26/01/2021.
} 
para o compartilhamento de fotos e vídeos instantâneos feitos pelo próprio usuário. O aplicativo, que pode ser baixado gratuitamente e instalado em smartphones e computadores pessoais, disponibiliza filtros e efeitos digitais para tratamento e edição das imagens, além de diversos outros recursos que possibilitam novas formas de comunicação e sociabilização, permitindo que cenas do cotidiano sejam compartilhadas e comentadas entre seus usuários e também entre usuários de outras redes sociais, tais como Facebook e Twitter.

Acreditamos que esse seja um espaço em que o atleta pode ser o responsável pela divulgação da sua imagem, sem necessariamente seguir orientações de marketing de patrocinadores, mesmo que esses exerçam, de alguma maneira, influência sobre a produção de suas imagens (GEURIN-EAGLEMAN; BURCH, 2016). Analisar as fotografias postadas pelas próprias lutadoras de MMA pode apontar resistências ou não aos modos midiáticos de exibição de gênero, que, segundo Goffman (1988), são caracterizados por normalizações que ratificam preconceitos e estereótipos em torno da mulher.

Para tanto, nos apoiamos nos debates pós-estruturalistas, especialmente aqueles que tratam do corpo e das discussões sobre gênero (LOURO, $1997 \mathrm{e}$ MEYER, 2004). Esses debates nos ajudam a pensar as relações de saber e poder, a centralidade da linguagem e a produção sociocultural do sujeito (SILVA, 2011).

Destarte, buscando responder nosso questionamento sobre a inserção das mulheres nas lutas de MMA, escolhemos lançar nosso olhar para as representações midiáticas, mais especificamente sobre as postagens no perfil público de lutadoras MMA - campeãs ou ex-campeãs do UFC - na mídia social Instagram. Nos interessa compreender de que maneiras as atletas de MMA usam esse meio virtual para comunicação e como ferramenta para construir suas marcas pessoais. Essa escolha pelo Instagram se justifica por ser, atualmente, a principal mídia social para compartilhamento de fotos, canal que dá ênfase à linguagem não verbal, como é o caso da fotografia - fonte pouco usual nos estudos sobre gênero e artes marciais mistas.

\section{METODOLOGIA}

Inicialmente, identificamos as campeãs e ex-campeãs do UFC, em todas as categorias de peso (palha, galo e pena) nas quais, até o momento da realização da coleta (abril de 2018), havia a participação feminina. Posteriormente, foram visualizadas e selecionadas as fotografias postadas em quatro períodos: uma semana antes de uma determinada luta, uma semana depois, três meses antes e um mês após a mesma luta. Definimos como critério de escolha da luta de cada atleta, aquela em que conquistou ou manteve o cinturão ${ }^{6}$. No caso de lutadoras que venceram mais de uma dessas lutas, o critério de escolha foi de visibilidade midiática.

Para elaboração do instrumento de análise das imagens, inicialmente usamos um esquema de codificação baseado nas definições teóricas estabelecidas

6 Premiação simbólica típica do mundo dos esportes de combate, é a honraria máxima dada ao campeão ou campeã de cada categoria do UFC. 
por Goffman (1988). A categorização das imagens foi elaborada em um processo inicialmente individualizado, no qual os pesquisadores analisaram uma amostra aleatória de imagens e identificaram diversos temas que serviram como referência para o desenvolvimento do instrumento de análise com categorias redefinidas e expandidas a partir de estudos anteriores (HATTON; TRAUTNER, 2011; KIM; SAGAS, 2014; SMITH; SANDERSON, 2015).

Posteriormente, as codificações foram analisadas, agora coletivamente, buscando ajustar as categorias temáticas a partir da afinidade dos temas dentro da categoria e entre as categorias, ajustando-as quanto necessário - ou seja, mover itens para uma categoria mais apropriada ou mesclar duas categorias se os temas fossem sobrepostos. Finalmente, através de uma sessão de discussão, os pesquisadores trocaram seus resultados de codificação, discutiram suas categorias e resolveram seus conflitos, concluindo assim o instrumento de análise das imagens.

Cada fotografia foi codificada para os seguintes itens: 1) cenário - identificar os diversos locais em que as fotos são produzidas (Figura 1); 2) personagens da foto - observar os personagens presentes nas fotos postadas pelas lutadoras (Figura 2); 3) toque feminino - observar a ocorrência de toques descritos por Goffman (1988) como toques característicos de representação do feminino (sem toque, toque casual, toque provocativo sensual); 4) divulgação - se a foto postada faz algum tipo de divulgação da marca UFC; 5) vestimenta - observar o quanto a roupa revela o corpo e sensualidade da lutadora; 6 ) tipo de foto/foco - identificar o tipo de foto mais comumente postada (selfie, rosto, meio corpo, corpo todo, só o corpo com o rosto escondido); 7) atividade - observar se são fotos das lutadoras em alguma ação esportiva/prática corporal ou são fotos sem ação esportiva; 8) marcas hegemônicas de gênero - observar a presença de elementos que demarcam referências de uma feminilidade hegemônica; 9) emancipação - observar gestos e olhares superiores que transmitem independência, sucesso.

A análise das imagens foi realizada separadamente por dois analisadores (uma mulher e um homem) e, buscando verificar a concordância entre os dois analisadores, usamos o Coeficiente de Correlação Intraclasse (ICC), comumente utilizado para avaliar confiabilidade entre avaliadores. $O$ valor de concordância para todas as categorias - exceto uma - indicou uma excelente concordância entre os analisadores. A categoria "ritualização da subordinação" teve concordância satisfatória entre os analisadores.

Ressaltamos que as imagens utilizadas na análise foram aquelas postadas em perfil público do Instagram. Toda pessoa, ao criar uma conta no aplicativo, precisa concordar com os termos de uso ${ }^{7}$ do aplicativo. Ao optar por um perfil público, o usuário está ciente de que suas fotografias serão de acesso público. Esta pesquisa foi aprovada pelo Comitê de Ética e seu Certificado de Apresentação para a Apreciação Ética (CAAE) está registrado no Sistema CEP/CONEP sob o número 80620317.8.0000.5196.

7 Termos de uso do Instagram em vigor a partir de 19 de janeiro de 2013. Disponível em: https://pt-br.facebook.com/ help/instagram/155833707900388/?helpref=hc fnav. Acesso em: 10 jul. 2020. 


\section{APRESENTAÇÃO E ANÁLISE DOS DADOS}

O escopo de análise desta pesquisa é composto por 251 imagens, somadas as imagens de nove lutadoras, postadas nos quatro períodos apresentados na metodologia. O quantitativo de imagens gerou muitos dados e tabelas, pois cada imagem foi analisada considerando cada item do instrumento de análise proposto. Assim, apresentaremos, em formato de tabela, os dados de frequência e porcentagem das postagens de cada lutadora, em cada um dos quatro períodos da análise. Os demais achados referentes às categorias que compunham o instrumento de análise serão apresentados e discutidos acompanhados de três imagens representativas dos diferentes dados cruzados entre elas. Além de exemplificar, as imagens foram colocadas para ajudar na visualização mais concreta de cada categoria e suas classificações. Por isso, abaixo de cada imagem está o primeiro nome da atleta e a classificação da imagem dentro da categoria analisada.

A Tabela 1 apresenta o nome das nove lutadoras que identificamos como campeãs ou ex-campeãs do UFC e um panorama geral de como as lutadoras usaram o Instagram dentro do período analisado. Percebe-se que as lutadoras Joanna Jedrzejczyk, Carla Esparza e Cris Cyborg são responsáveis por mais de $70 \%$ das imagens analisadas. Ainda na Tabela 1, apresentamos a frequência de postagens por período de cada uma das nove lutadoras.

Tabela 1- Cruzamento dos dados lutadora e período

\begin{tabular}{|c|c|c|c|c|c|c|}
\hline \multicolumn{7}{|c|}{ Período } \\
\hline \multirow[b]{2}{*}{ LUTADORAS } & \multirow{2}{*}{$\begin{array}{c}\text { três } \\
\text { meses } \\
\text { antes da } \\
\text { luta }\end{array}$} & \multirow{2}{*}{$\begin{array}{c}\text { uma semana } \\
\text { antes da } \\
\text { luta }\end{array}$} & \multirow{2}{*}{$\begin{array}{l}\text { semana } \\
\text { depois } \\
\text { da luta }\end{array}$} & \multirow{2}{*}{$\begin{array}{c}\text { um mês } \\
\text { depois da } \\
\text { luta }\end{array}$} & \multicolumn{2}{|c|}{ Total } \\
\hline & & & & & $\mathbf{F}$ & $\%$ \\
\hline Amanda Nunes & 2 & 2 & 15 & 4 & 23 & 9,2 \\
\hline Carla Esparza & 24 & 23 & 6 & 9 & 62 & 24,7 \\
\hline Cris Cyborg & 12 & 15 & 12 & 14 & 53 & 21,1 \\
\hline Germaine de Randamie & 1 & 1 & 0 & 0 & 2 & 0,8 \\
\hline Holly Holm & 4 & 2 & 2 & 5 & 13 & 5,2 \\
\hline Joanna Jedrzejczyk & 7 & 36 & 10 & 9 & 62 & 24,7 \\
\hline Miesha Tate & 4 & 6 & 2 & 2 & 14 & 5,6 \\
\hline Ronda Rousey & 1 & 6 & 0 & 2 & 9 & 3,6 \\
\hline Rose Namajunas & 0 & 4 & 9 & 0 & 13 & 5,2 \\
\hline Total & 55 & 95 & 56 & 45 & 251 & 100,0 \\
\hline
\end{tabular}

Na Tabela 2 são apresentados os dados referentes à frequência das postagens específicas por período de análise somadas às imagens de todas as lutadoras. No geral, as lutadoras postaram mais fotos no período que compreende uma semana antes da luta, dado que corresponde ao esperado, considerando que os atletas usam as mídias sociais para divulgação das suas marcas; assim, é esperado que as lutadoras usem o Instagram para divulgar e promover suas lutas. Considerando as duas tabelas, notamos que Amanda Nunes e Rose Namajunas destoam das demais. 
Das 23 imagens da Amanda Nunes, apenas duas foram postadas na semana que antecede a sua luta, e Rose Namajunas postou quatro, aproximadamente um terço do total das suas 13 postagens analisadas.

Tabela 2 - Frequência e porcentagens referentes aos quatro períodos de análise

\begin{tabular}{lcc}
\hline PERÍODO & F & $\%$ \\
\hline Três meses antes da luta & 55 & 21,9 \\
Semana antes da luta & 95 & 37,8 \\
Semana depois da luta & 56 & 22,3 \\
Um mês depois da luta & 45 & 17,9 \\
\hline Total & $\mathbf{2 5 1}$ & $\mathbf{1 0 0 , 0}$ \\
\hline
\end{tabular}

Fonte: Autores.

Figura 1 - Categoria "cenário"

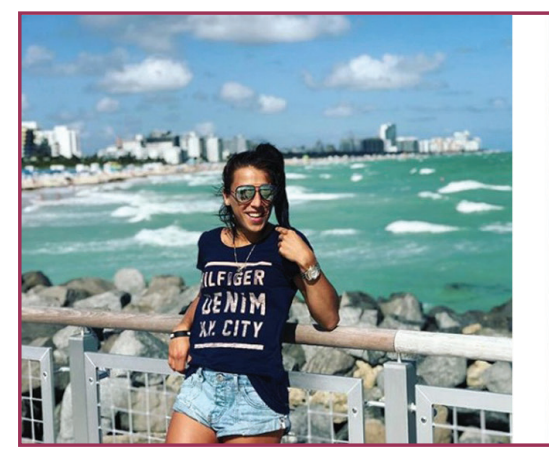

Joanna, paisagem natural

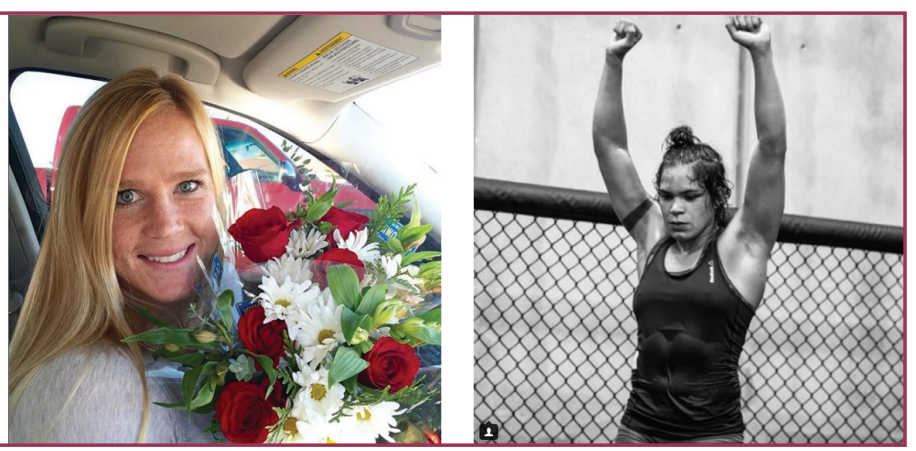

Holly, espaço público Fonte: Instagram (2018)

Observando o cenário das fotos de cada atleta e comparando os diversos locais em que as fotos foram produzidas, nota-se certa equivalência do contexto pessoal (paisagem natural, casa e espaço público) com o contexto profissional das lutadoras (local de treino, octógono, palco das pesagens, estúdio e pôster). Esses dados corroboram, em certa medida, os dados de estudos anteriores que evidenciaram o uso das mídias sociais para compartilhamento de diversos aspectos da vida pessoal dos atletas (SMITH; SANDERSON, 2015; SANDERSON, 2014). Esses autores indicam que os atletas tendem a usar essas plataformas para a função "social" inerente a esses meios, secundarizando sua utilização como estratégia de promoção corporativa e demonstração dos seus níveis de treinamento. Todavia, verificamos poucas postagens que fazem referência ao contexto familiar $(5,2 \%)$, o que difere dos estudos sobre a representação da mulher atleta na mídia esportiva. Esses dados sugerem que as mídias sociais oferecem possibilidade de as lutadoras exercerem maior controle sobre a representação de suas imagens e se autoapresentarem diferentemente das normas de gênero que persistentemente ainda são reforçadas pela mídia esportiva. 
Figura 2 - Categoria "personagem da foto"

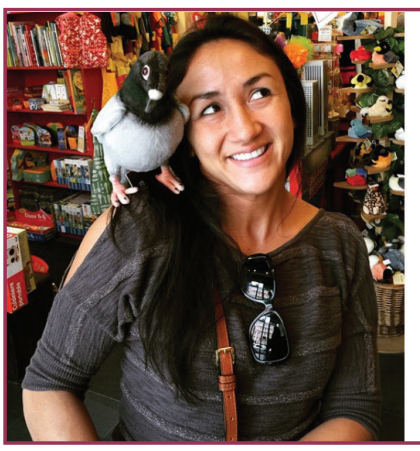

Carla, atleta

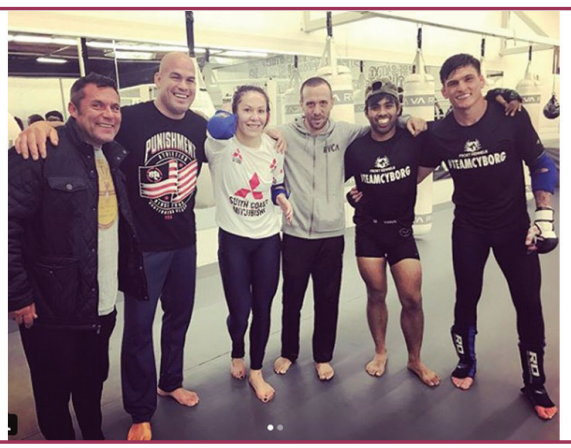

Cris, atleta e equipe

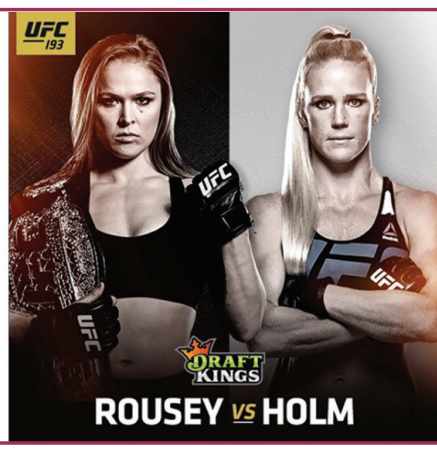

Ronda, atleta e adversária

Fonte: Instagram (2018)

No contexto contemporâneo, de grande ênfase nas mídias sociais, em que podemos performar nossas personalidades e encenar nossas vidas na visibilidade das telas interconectas (SIBILIA, 2008), já era de se esperar que os personagens principais das postagens fossem, em maior parte, fotos somente com as próprias lutadoras (41,4\%). As imagens com amigos e companheiros de equipe - que, dependendo do contexto, são os mesmos - somam 25,1\%. Apesar de ser um esporte individual, a preparação para competir em alto nível exige das lutadoras muita dedicação e tempo aos treinos rigorosos, e as academias de lutas geralmente são descritas pelos participantes como um segundo lar. $O$ tempo que passam juntos cria fortes laços de amizade, além de colaborar com a própria formação enquanto lutadora (ANDREASSON; JOHANSSON, 2018; WACQUANT, 2002).

Um dado curioso é que fotos com as adversárias (7,2\%), seja nos pôsteres de divulgação seja nas imagens de pesagem, são mais postadas do que as fotos com familiares (5,2\%). Geralmente são imagens com as lutadoras lado a lado, frente a frente, se encarando, provocando umas às outras. Imagens que vão construindo guerreiras corajosas, colaborando com a construção de narrativas de batalhas espetaculares.

Figura 3 - Categoria "toque feminino"

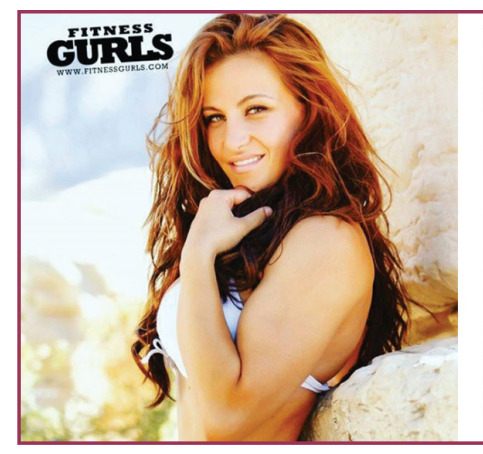

Miesha, toque provocativo sensual

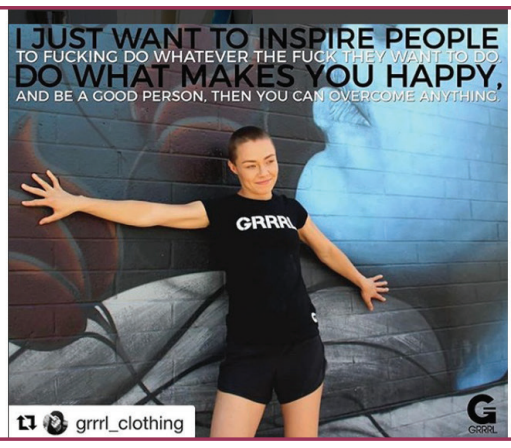

Rose, toque casual

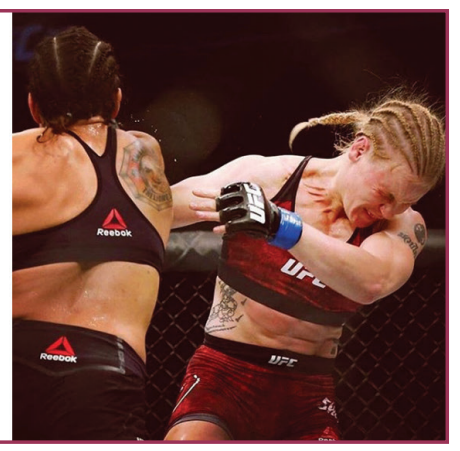

Amanda, toque provocativo esportivo

Fonte: Instagram (2018)

A categoria toque feminino ${ }^{8}$ é uma versão revisada do conceito de "toque feminino" de Goffman (1988), que identificou em seu trabalho a gestualidade do

8 A denominação do "feminino" aqui e nos estudos citados está vinculada ao uso tradicional e hegemônico deste termo. A ideia foi observar no nosso estudo a permanência ou não dessas características nas imagens, para analisarmos a possível ressignificação e resistência apresentada pelas atletas. 
toque feminino, ou seja, as mulheres eram quase sempre representadas tocando a si mesmas, com a mão na boca, ou tocando outros objetos de forma delicada. $\mathrm{O}$ toque feminino foi classificado por ele enquanto toque casual e toques provocativos sensuais. Na primeira postura, o corpo feminino é considerado frágil e fraco, na segunda, pode sugerir sensualização das imagens. Em concordância com achados anteriores (SMITH; SANDERSON, 2015), nesta amostra identificamos 107 toques casuais típicos do comportamento feminino observados por Goffman (1988) e apenas dois toques provocativos sensuais.

Considerando a especificidade dos esportes de combate, em que tocar e ser tocada é inevitável (socos, chutes, estrangulamentos), esperávamos que nas imagens outro tipo de toque fosse observado, o que categorizamos como "toque provocativo esportivo". Apenas $6,2 \%$ das postagens apresentam algum tipo desse toque provocativo, seja nos combates ou nas provocações comumente apresentadas no momento da pesagem ou nas coletivas de imprensa.

Essa pouca prevalência de imagens com toque provocativo esportivo pode ser uma estratégia para minimizar críticas e polêmicas, que ainda são feitas às competições de MMA, relacionadas à violência e agressividade daqueles que consideram a modalidade como descivilizada (ANDREASSON; JOHANSSON, 2018). Além disso, considerando as persistentes normatizações de comportamento implicadas às mulheres, que as direcionam para uma feminilidade hegemônica, que seja dócil, recatada e bela; a agressividade aponta para outro sentido. Ou seja, provavelmente uma gama de fatores colabora para a pouca divulgação de imagens dessas mulheres em momentos esportivos com uma agressividade mais explícita, incluindo a construção do "ser mulher". Considerando outras categorias analisadas, o toque provocativo esportivo parece ser um ponto de maior invisibilidade na divulgação dessas atletas.

Figura 4 - Categoria "divulgação"

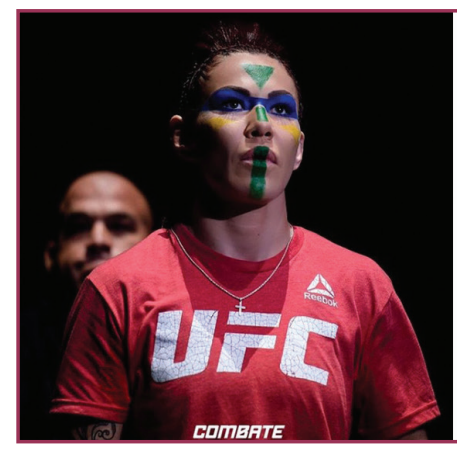

Cris, divulgação direta

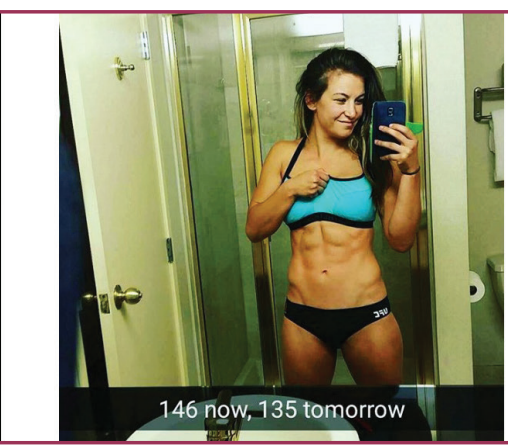

Miesha, divulgação indireta

Fonte: Instagram (2018)

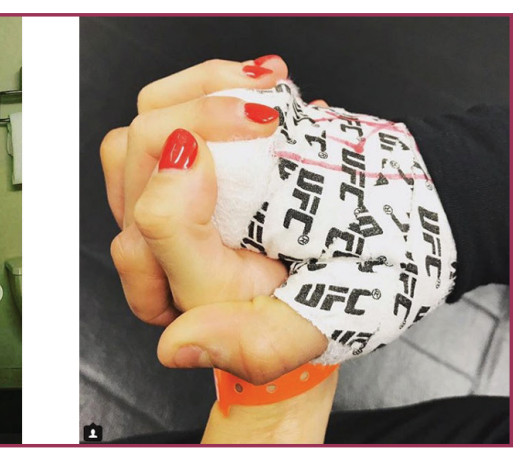

Amanda, divulgação indireta

No conjunto das imagens analisadas, $47,8 \%$ promovem divulgação direta ou indireta referente ao UFC. Quando analisamos as postagens individuais de cada lutadora, quase todas têm mais da metade das fotos fazendo divulgação direta ou indireta (Carla Esparza, Cris Cyborg, Germaine de Randamie, Miesha Tate, Ronda Rousey e Rose Namajunas), as demais (Amanda Nunes, Holly Holm e Joanna Jedrzejczyk) apresentam um terço de suas imagens fazendo referência publicitária ao UFC. 
O MMA exemplifica bem as transformações e adaptações ao mundo globalizado, à sociedade de consumo e aos meios de comunicação que incidem influências sobre a dinâmica das modalidades esportivas (GALLATTI et al., 2018). Hoje, vemos o enfraquecimento dos clubes esportivos e o crescimento das organizações empresariais no controle de universo esportivo - regras, torneios e vinculação contratual dos atletas. Alia-se a isso a tendência de que atletas e organizações esportivas estão cada vez mais ativos em sites de mídias sociais, promovendo e atraindo patrocinadores (GEURIN-EAGLEMAN; BURCH, 2016), e o Instagram impressiona com impacto positivo para as marcas que fazem uso da sua plataforma (TROUNG, 2014).

Figura 5 - Categoria "vestimenta"

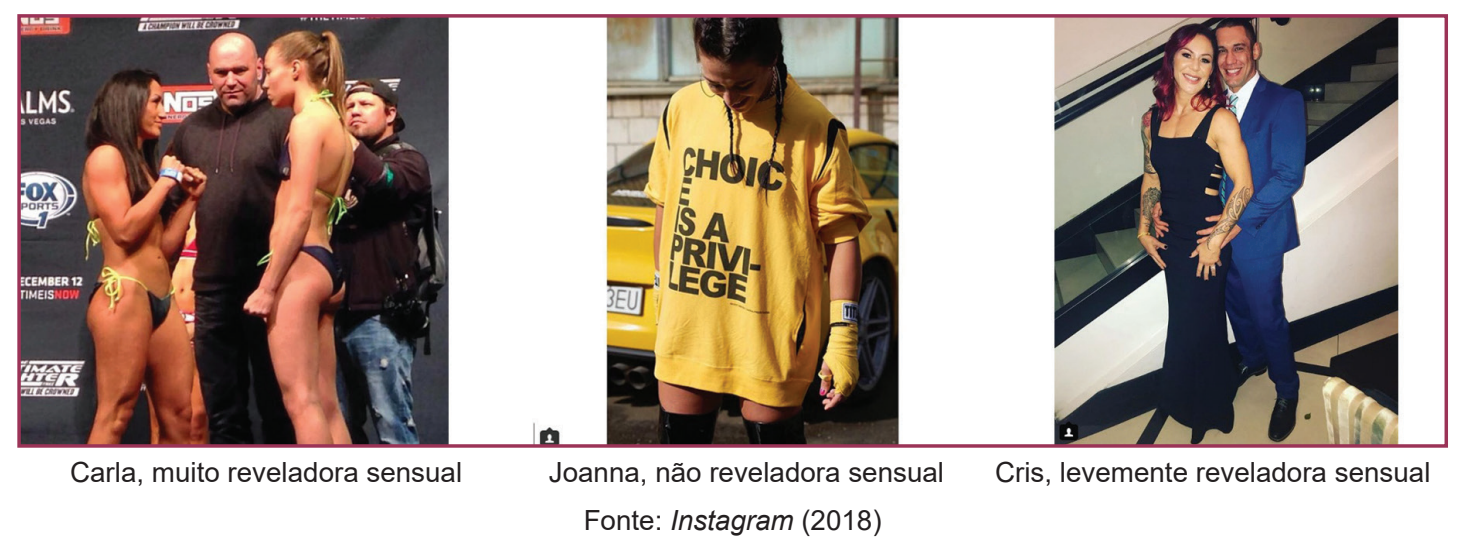

$\mathrm{Na}$ categoria vestimenta, $31,1 \%$ das postagens apresentam as lutadoras em roupas não reveladoras; levemente reveladora sensual e não sensual somam 36,3 $\%$; reveladora muito sensual e não sensual somam $19,1 \%$; muito reveladora sensual e não sensual somam $5,2 \%$. As demais imagens $(8,4 \%)$ foram codificadas como não aplicável, já que não foi possível identificar o tipo de vestimenta usada pelas lutadoras.

Apesar da baixa ocorrência de postagens com exposição e sensualização do corpo das lutadoras, observa-se uma predominância da ocorrência dessas imagens em locais específicos do contexto esportivo - a imagem acima da lutadora Carla Esparza é representativa dessa constatação. Sete das oito postagens de lutadoras com roupas muito reveladoras e sensuais têm como cenário da foto contextos esportivos, tais como: local de treino e pôster (uma postagem cada) e palco das pesagens (cinco postagens). A exposição do corpo das lutadoras de MMA durante a pesagem pode ser justificada pela necessidade das atletas "baterem o peso" da categoria. No entanto, não pudemos comprovar até que ponto isso é uma necessidade ou um comportamento influenciado por uma objetivação do corpo da mulher; considerandose que, em uma sociedade heteronormativa, as questões corporais das mulheres estão relacionadas ao olhar sexualizado dos homens, ou seja, a relação da mulher com seu corpo sofre constantes pressões, e não está livre do olhar sexualizado em nenhuma circunstância (FREDRICKSON; ROBERTS, 1997). Segundo informações do site do ESPN Brasil $^{9}$, com as novas medidas adotadas por algumas comissões 
atléticas, a pesagem oficial acontece períodos antes da pesagem que é midiatizada, ou seja, a justificativa para os atletas mulheres e homens pesarem em trajes mínimos não é nenhuma necessidade específica do contexto esportivo. Acreditamos ser necessária uma comparação das exibições da pesagem de mulheres e homens lutadores para uma melhor compreensão dessa argumentação.

Nessa categoria, sobressaem-se as relações de poder presentes nesse esporte que se relacionam com as questões de gênero. $O$ uso de vestimentas reveladoras ou muito reveladoras parece não estar vinculado por acaso aos espaços de divulgação do UFC. Essa peculiar autoapresentação, vinculada à organização UFC, constitui uma forma deliberada e compulsória de espetacularização dos corpos dessas lutadoras. Por outro lado, observamos a diversidade de exposição apresentada nas fotos, inclusive o uso de roupas reveladoras em contextos que mostram agência dessas mulheres e o uso de não reveladoras em outros contextos, como é reforçado em outras categorias.

Figura 6 - Categoria "tipo de foto/foco"

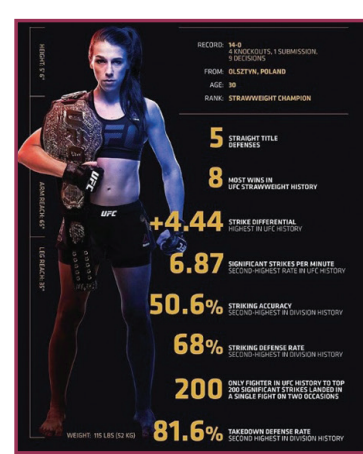

Joanna, corpo todo

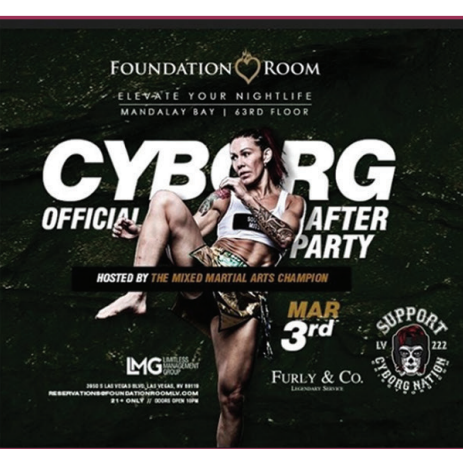

Cris, pernas

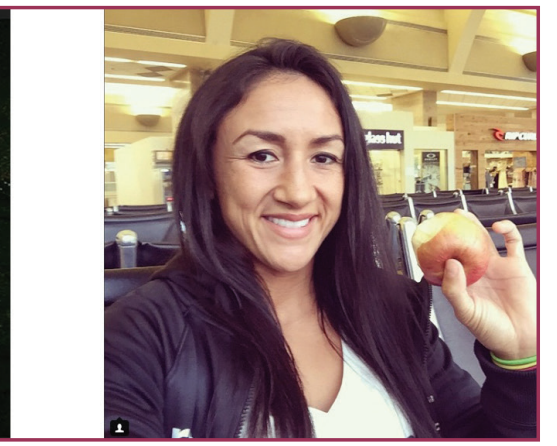

Carla, selfie

Fonte: Instagram (2018)

O foco das imagens analisadas é em grande parte do corpo todo e do rosto das atletas, 84 e 82 imagens respectivamente. As pouquíssimas imagens que focam em partes mais íntimas das atletas parecem sofrer influência do período de postagens das imagens, já que quase todas as imagens que focam nas pernas (cinco fotos), nos seios (duas fotos), no abdômen (duas fotos), foram postadas no período de uma semana antes da luta.

Observando o tipo de foto, a selfie, embora seja um fenômeno amplamente disseminado nas mídias sociais, sendo considerado o tipo de imagem mais produzido e exibido em todo o planeta (SIBILIA, 2008), no caso da amostra analisada não teve uma incidência significativa. As lutadoras se autoapresentam, na maioria das postagens, de corpo inteiro (115 fotos) ou por fotos de meio corpo (88 fotos). As selfies somam apenas 19 imagens do conjunto de 251 postagens. Para Smith e Sanderson (2015), a preferência dos atletas por fotos que não sejam selfie pode ser justificada pela necessidade de apresentar visualmente um lado diferente de suas vidas. Nesse caso, uma selfie, por concentrar unicamente um assunto da fotografia, tornaria a leitura do contexto limitada (SMITH; SANDERSON, 2015). Ainda segundo os autores, a preferência dos atletas por fotos de corpo inteiro também pode ser atribuída ao orgulho de apresentarem corporalmente o resultado do intenso trabalho de treinamento. No entanto, no caso das lutadoras em análise, há que se destacar 
a influência da organização na escolha do tipo de foto que suas atletas divulgam, já que, das 115 fotos de corpo inteiro, 52 divulgam direta ou indiretamente o UFC.

Figura 7 - Categoria "atividade"

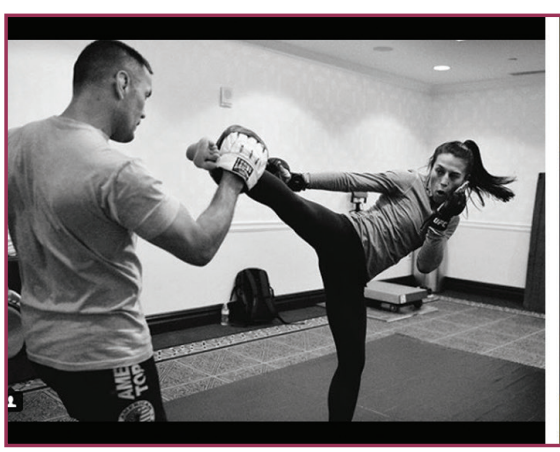

Joanna, ativa

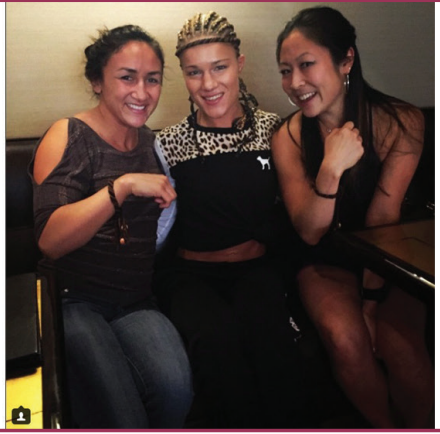

Carla, passiva

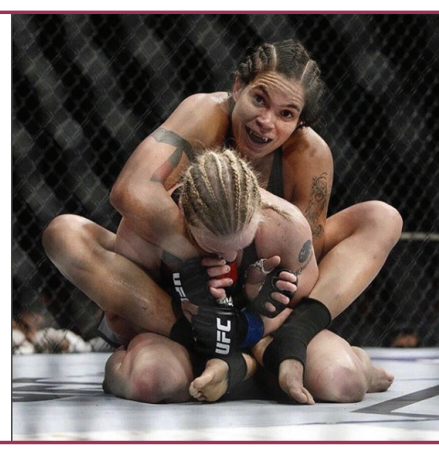

Amanda, ativa

Fonte: Instagram (2018)

$\mathrm{Na}$ categoria atividade, os dados apresentam 193 postagens codificadas em poses sem ação esportiva contra 58 em poses de ações esportivas. Essa predominância não sofre interferência do período das postagens. Mesmo na semana que antecede as lutas - hipoteticamente as imagens das atletas em ações atléticas poderiam promover suas lutas - as postagens são mais de poses passivas (69 postagens) em relação às poses ativas (26 postagens). Apesar de terem postado mais fotos no contexto esportivo, as imagens estão relacionadas principalmente a divulgação, coletivas de impressa e afins. É preciso ressaltar que os eventos de MMA são promocionais e estão cercados pela mídia esportiva. Esses dados, em certa medida, corroboram evidências de estudos anteriores (GEURIN-EAGLEMAN; $\mathrm{BURCH}, 2016)$ que, ao analisarem imagens de mulheres e homens atletas postadas em suas redes sociais, evidenciaram que as mulheres se autoapresentam mais em poses sem ação esportiva quando comparadas com atletas homens. Essa predominância também é evidenciada na mídia esportiva (HARDIN et al., 2002; DADDARIO, 1994; DUNCAN, 1990; MESSNER, 1988), que quase sempre retrata as mulheres atletas em poses paradas em vez de ações atléticas, reforçando, de certa maneira, os estereótipos de gênero.

Aqui não podemos afirmar que as lutadoras reproduzem as representações visuais encontradas nos meios de comunicação como resultado de normas culturais, ou se é uma decisão consciente de se autoapresentar em poses sem ação esportiva, possibilitando apresentar suas situações cotidianas para além das lutas. Outra possibilidade que precisa ser considerada é a preferência do uso dos vídeos para a publicização de ações atléticas, considerando a facilidade técnica para se produzir e publicar esse formato de mídia com os diversos e dinâmicos recursos oferecidos pelo Instagram.

Todas as lutadoras da nossa análise, com exceção de Germaine de Randamie - atleta com apenas duas postagens na análise -, postaram fotos de seus treinos e de suas ações no octógono. Parece que é importante para as lutadoras mostrarem o processo particular de construção do corpo de uma lutadora, processo que resulta de um longo processo de inculcação do habitus pugilístico (WACQUANT, 2002). 
Figura 8 - Categoria "marcas hegemônicas de gênero"

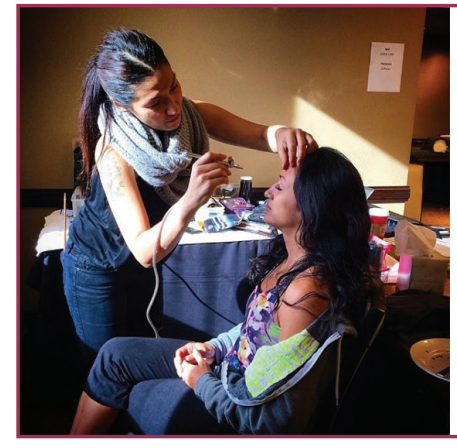

Carla, marcante

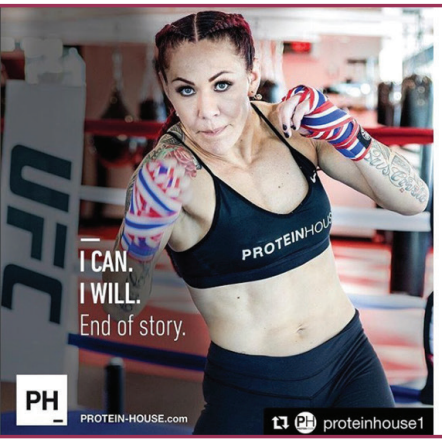

Cris, marcante

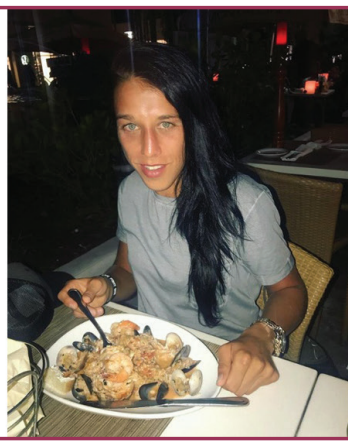

Joanna, sutil

Fonte: Instagram (2018)

Buscando evidenciar as marcas de gênero hegemônicas, analisamos as imagens com o olhar centrado nas normas culturais que caracterizam a feminilidade normativa. Aqui o objetivo era buscar evidências de que, de alguma forma, as atletas precisam mostrar a ambivalência de ser mulher lutadora, forte e feminina, e como os períodos de postagens exercem influência sobre esses aspectos. Foram identificadas 172 imagens codificadas com marcas sutis demarcadoras de feminilidade hegemônica e 42 imagens com traços marcantes da feminilidade hegemônica, 19 delas postadas uma semana antes da luta. Carla Esparza (15 fotos) e Cris Cyborg (14 fotos) são as lutadoras que postaram mais imagens com traços marcantes de feminilidade normativa. Amanda Nunes e Rose Namajunas não postaram nenhuma foto codificada nessa categoria.

As imagens analisadas mostram performances de gênero distintas. Nem todas as lutadoras se autoapresentam dentro de uma concepção hegemônica de feminilidade. Como nos alertam Louro (1997) e Meyer (2004), essa identidade é negociada e construída por muitos meios. Em estudo sobre a construção corporal de mulheres fisiculturistas, Oliveira, Silva e Almeida (2019) identificaram um processo de desconstrução da creditada fragilidade "inata" do corpo feminino. Por outro lado, verificaram que ainda há uma expectativa, que recai sobre essas mulheres fisiculturistas, de comportamentos típicos de uma feminilidade hegemônica, tais como roupas reveladoras, comportamentos dóceis e limites para o desenvolvimento muscular. Nessa mesma direção, Jardim (2018) também evidenciou essa pluralidade feminina entre as lutadoras brasileiras de MMA. A autora destaca que essa pluralidade não existe sem tensão. Seu estudo constatou que algumas lutadoras se preocupam que suas imagens sejam associadas à heteronormatividade, e para isso exibem em seus corpos valores tradicionais associados à feminilidade: unhas pintadas, uso de batom, saias e vestidos esportivos nas lutas e treinamentos (JARDIM, 2018). A possibilidade da pluralidade, apresentada nas imagens analisadas, parece associada a questões socioculturais relacionadas à participação das mulheres em diversos espaços. A própria participação no UFC precisou ser conquistada e foi resultado da eficiência dessas mulheres e do reconhecimento social de sua atuação.

Deixamos claro que a existência das marcas aqui analisadas não significa um demérito, uma fraqueza ou uma falta de vontade de participar do esporte. Na nossa visão, a existência dessas marcas - e de outras tantas - mostra que nos últimos anos 
a participação esportiva das mulheres tem sido potencializada e potencializadora de mudanças mais amplas da sociedade e do próprio esporte. A presença dessa pluralidade auxilia na produção de representatividade, sendo importante seu reconhecimento e seu fortalecimento.

Figura 9 - Categoria "emancipação"

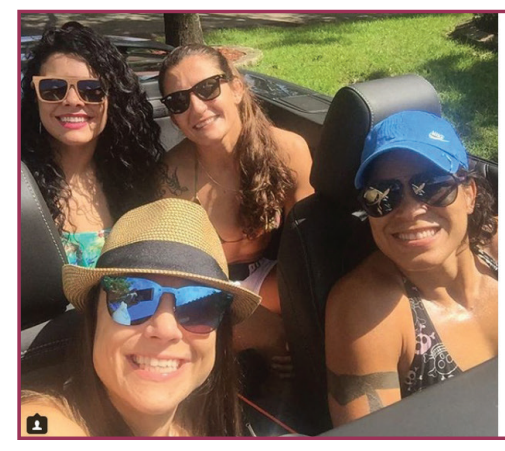

Amanda, emancipação

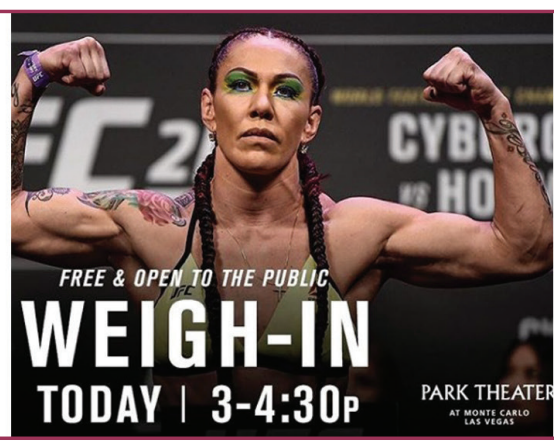

Cris, emancipação

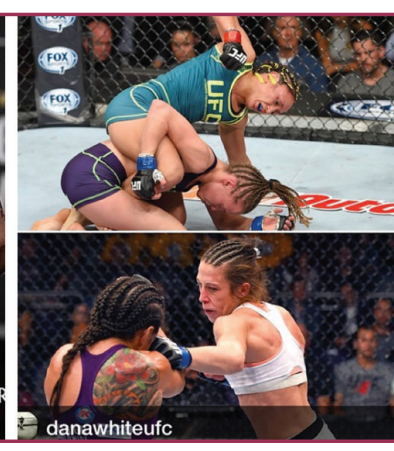

Carla, emancipação

Fonte: Instagram (2018)

Nessa categoria buscamos identificar elementos visuais que transmitem a ideia de emancipação das mulheres lutadoras de MMA. Observamos 191 imagens codificadas como significando emancipação da mulher. Cruzando os dados de emancipação com o cenário das fotos, observa-se as imagens representativas de emancipação tanto nos espaços de contextos esportivos (99 postagens) quanto em espaços fora desse contexto (81 postagens), e 11 postagens em que não pudemos identificar o cenário da foto. Esses dados corroboram os achados de Sena Jardim e D'Avila Neto (2010), que, analisando a representação do feminino em cartões-postais contemporâneos, evidenciaram uma representação de emancipação da mulher, transmitida por gestos e olhares superiores, combinando sensualidade e sedução com independência, ousadia e sucesso profissional/financeiro.

As imagens da nossa análise, codificadas como representativas de emancipação da mulher, subvertem as normas tradicionais de gênero. São imagens de mulheres fortes, seguras e confiantes; se inserindo e conquistando espaço em uma modalidade de grande reserva masculina; expondo suas conquistas no esporte e suas premiações; e conquistas relacionadas ao consumo. É importante destacar que a emancipação que estamos considerando aqui é aquela relacionada aos aspectos individuais, fundada numa concepção individualista de empoderamento.

A participação das mulheres no esporte favorece o senso de competência, confiança, independência e controle sobre seus corpos e vidas. No entanto, há muito a aprender sobre como o empoderamento é processado durante experiências esportivas e quais elementos contextuais do esporte afetam o empoderamento e a vida das mulheres (LIM; DIXON, 2018). No caso analisado, percebemos nesse processo certa necessidade colocada pela própria dinâmica do esporte de demonstrar empoderamento e dominação - como nos exemplos de imagens de "encaradas" para fotos de divulgação da luta. Assim, as atletas negociam entre imagens de uma emancipação mais agressiva e uma emancipação vinculada à independência. 


\section{CONSIDERAÇÕES FINAIS}

Embora todas as lutadoras analisadas tivessem vínculo contratual com a organização UFC, não foi observado padronização nas imagens postadas. Evidenciamos que o Instagram é, aparentemente, usado pelas lutadoras com a finalidade "social" característica das mídias sociais, como foi possível notar nos itens analíticos sobre "cenário e "personagens". No entanto, como evidenciamos nas discussões sobre a "divulgação", a marca do UFC aparece com grande frequência nas imagens de todas as lutadoras, dados que apontam para o conceito de marca do atleta de Arai, Ko e Ross (2014), que definiram que o atleta, enquanto pessoa pública, estabelece seu próprio significado e valor simbólico usando seu nome, seu rosto ou outros elementos de marca no mercado. O modelo de imagem de marca do atleta definido por eles inclui as dimensões atléticas, aparência atraente e estilo de vida comercial, que demonstramos na análise e cruzamento do "tipo de foto/foco", "atividade" e "emancipação".

No geral, as imagens analisadas não apresentam a tendência persistente na cobertura da mídia esportiva de sexualização do corpo de mulheres atletas. Percebemos essa tendência pelas análises dos itens "toque feminino", "vestimenta" e "marcas hegemônicas de gênero". No entanto, quando cotejamos a presença de "marcas hegemônicas de gênero" e a "vestimenta" com o "cenário", as imagens que remetem a essa representação sexualizada foram observadas no contexto específico do trabalho direto com o UFC: momento da pesagem e imagens de divulgação direta do UFC. Observamos também fotos com o cenário de locais públicos; dessas, a maioria parece ser o uso da imagem da atleta divulgando outras marcas, com alguns casos de sensualização e com marcas hegemônicas de feminilidade. Também não evidenciamos representação baseada em normas e expectativas convencionais de comportamento de gênero que delegam à mulher o cuidado da casa e a maternidade. Outrossim, as imagens analisadas mostram uma feminilidade plural.

Desta forma os nove itens analisados, construídos a partir da proposta de Goffman (1988) e da especificidade da nossa pesquisa, nos auxiliaram a entender a dinâmica de autoapresentação dessas lutadoras de MMA no Instagram. Destacamos a importância da contextualização e do entrecruzamento dos itens para revelar diversas relações de poder e resistências percebidas no conjunto de imagens.

Talvez, a liberdade que as lutadoras têm em controlar o tipo de foto que postam nas mídias sociais é oportunidade para resistir e subverter os significados e discursos que são normalizados pela mídia esportiva. Esse comportamento pode ser reflexo das mudanças culturais ocorridas nas últimas décadas, como resultado de movimentos sociais dentro e fora do mundo do esporte.

No entanto, éimportante ressaltar as limitações da atual pesquisa, considerando o universo de mulheres lutadoras de MMA; aqui focamos nosso olhar nas campeãs do UFC, o que talvez possibilite a elas melhores condições de resistência e menos influência sobre a exploração de suas imagens. Pesquisas futuras podem ampliar o número de lutadoras e organizações; comparar as imagens de lutadoras em diferentes níveis de desenvolvimento na carreira. Pesquisas futuras também podem direcionar 
a análise na interpretação que diferentes grupos fazem das imagens analisadas, bem como entrevistas autobiográficas com lutadoras buscando compreender suas motivações ou envolvimento estratégico potencializado ao decidir quais imagens serão publicadas.

\section{REFERÊNCIAS}

ANDREASSON, Jasper; JOHANSSON, Thomas. (Re)Negotiating violence. In: ANDREASSON, Jasper; JOHANSSON, Thomas. Extreme sports, extreme bodies. Cham: Palgrave Macmillan, 2018. p. 183-200.

ARAI, Akiko; KO, Jae Yong; ROSS, Stephen. Branding athletes: exploration and conceptualization of athlete brand image. Sport Management Review, v. 17, n. 2, p. 97106, May 2014.

DADDARIO, Gina. Chilly scenes of the 1992 Winter Games: the mass media and the marginalization of female athletes. Sociology of Sport Journal, v. 11, n. 3, p. 275-288, Jan. 1994.

DUNCAN, Margaret Carlisle. Sports photographs and sexual differences: images of women and men in the 1984 and 1988 Olympic Games. Sociology of Sport Journal, v. 7, n. 1, p. 22-42, Jan. 1990.

FREDRICKSON, Barbara; ROBERTS, Tomi-Ann. Objectification theory: toward understanding women's lived experiences and mental health risks. Psychology of Women Quarterly, v. 21, n. 2, p. 173-206, Jul. 1997.

GALATTI, Larissa Rafaela et al. Esporte Contemporâneo: perspectivas para a compreensão do fenômeno. Corpoconsciência, v. 22, n. 3, p. 115-127, set./dez., 2018.

GEURIN-EAGLEMAN, Andrea; BURCH, Lauren. Communicating via photographs: a gendered analysis of Olympic athletes' visual self-presentation on Instagram. Sport Management Review, v. 19, n. 2, p. 133-145, Apr. 2016.

GOELLNER, Silvana Vilodre; JAEGER, Angelita Alice; FIGUEIRA, Márcia Luiza Machado. Mulheres e esporte: invisibilidades visíveis no skate e no fisiculturismo. Gênero, v. 10, n. 2, p. 293-310, fev./jun., 2010.

GOELLNER, Silvana Vilodre; SILVA, Paula; BOTELHO-GOMES, Paula. A subrepresentação do futebol praticado por mulheres no jornalismo esportivo de Portugal: um estudo sobre a Algarve Women's Football Cup. Movimento, v. 19, n. 3, p. 171-189, jul./set., 2013.

GOFFMAN, Erving. Gender advertisements. New York: Harper Torchbooks, 1988.

HARDIN, Marie et al. The framing of sexual difference in Sports Illustrated for Kids editorial photos. Mass Communication and Society, v. 5, n. 3, p. 341-360, Nov. 2002.

HATTON, Eric; TRAUTNER, Mary Nell. Equal opportunity objectification? The sexualization of men and women on the cover of Rolling Stone. Sexuality \& Culture, v. 15, n. 3, p. 256278, Sept. 2011. 
JARDIM, Gabriel de Sena; D'ÁVILA NETO, Maria Inácia. Mulheres postadas: representações do feminino em cartões-postais publicitários (1990-1950/2000-2008). In: SEMINÁRIO INTERNACIONAL FAZENDO GÊNERO, 9, 2010: Diásporas, Diversidades, Deslocamentos. Anais eletrônicos... Florianópolis: Universidade Federal de Santa Catarina, 2010. Disponível em: http://www.fg2010.wwc2017.eventos.dype.com.br/resources/ anais/1277903057_ARQUIVO_MULHERESPOSTADAS.pdf. Acesso em: 26 fev. 2021.

JARDIM, Juliana. "Até vestidinho elas estão botando": problematizando padrões corporais, de gênero e sexualidades nas artes marciais mistas femininas. In: MUNDOS DE MULHERES, 13 \& FAZENDO GÊNERO, 11, 2017. In: Anais eletrônicos... Florianópolis: Universidade Federal de Santa Catarina, 2018. Disponível em: http://www.wwc2017. eventos.dype.com.br/resources/anais/1499459174_ARQUIVO_JulianaJardim_ST57.pdf. Acesso em: 26 fev. 2021.

KIM, Kayoung; SAGAS, Michael. Athletic or sexy? A comparison of female athletes and fashion models in Sports Illustrated Swimsuit Issues. Gender Issues, v. 31, n. 2, p. 123-141, Jun. 2014.

KIM, Kayoung; SAGAS, Michael.; WALKER, Nefertiti A. Replacing athleticism with sexuality: athlete models in Sports Illustred swimsuit issues. International Journal of Sport Communication, v. 4,n. 2, p.148-162, 2010.

KNIJNIK, Jorge Dorgman; SOUZA, Juliana Sturmer Soares. Diferentes e desiguais: relações de gênero na mídia esportiva brasileira. In: SIMÕES, Antonio Carlos; KNIJNIK, Jorge Dorgman. (Org.). O mundo psicossocial da mulher no esporte: comportamento, gênero e desempenho. São Paulo, Aleph, 2004. p. 191-212.

LIM, So Youn; DIXON, Marlene. A conceptual framework of sport participation and women's empowerment. Managing Sport and Leisure, v. 22, n. 5, p. 400-413, Jul. 2018.

LOURO, Guacira Lopes. Gênero, sexualidade e educação: uma perspectiva pósestruturalista. Petrópolis, RJ: Vozes, 1997

MESSNER, Michael. Sports and male domination: the female athlete as contested ideological terrain. Sociology of Sport Journal, v. 5, n. 3, p. 197-211, Jan. 1988.

MEYER, Dagmar Estermann. Teorias e políticas de gênero: fragmentos históricos e desafios atuais. Revista Brasileira de Enfermagem, v. 57, n. 1, p. 13-18, jan./fev. 2004.

MILLEN NETO, Alvaro Rego; GARCIA, Roberto Alves; VOTRE, Sebastião Josué. Artes marciais mistas: luta por afirmação e mercado da luta. Revista Brasileira de Ciências do Esporte, v. 38, n. 4, p. 407-413, out./dez. 2016.

MISKOLCI, Richard. Sociologia digital: notas sobre pesquisa na era da conectividade.

Contemporânea, v. 6, n. 2, p. 275-279, jul./dez. 2016.

MÜHLEN, Johanna Coelho Von; GOELLNER, Silvana Vilodre. Jogos de gênero em Pequim 2008: representações de feminilidades (re)produzidas pelo site Terra. Revista Brasileira de Ciências do Esporte, v. 34, n. 1, p. 165-184, jan./mar. 2012.

OLIVEIRA, Valleria Araujo; SILVA, Ana Márcia; ALMEIDA, Dulce Filgueira de. Entre um ideal ético e estético: as atletas em campeonatos de musculação fitness e fisiculturismo. Pensar a Prática, v. 22, p. 3-11, 2019.

PEREIRA, Erik Giuseppe Barbosa; PONTES, Vanessa Silva; RIBEIRO, Carlos Henrique de Vasconcellos. Revelações dos fotógrafos esportivos brasileiros sobre relações de gênero.

Motricidade, v. 11, n.1, p. 126-134, 2015. 
SANDERSON, Jimmy. Just warming up: Logan Morrison, twitter, athlete identity, and building the brand. In B. Brummett \& A. W. Ishak (Eds.), Sport and identity: New agendas in communication. New York, NY: Routledge, 2014. p. 208-223.

SHALLER, Jessica. Female athletes in the media: under representation and inadequacy. The Review: A Journal of Undergraduate Student Research, v. 8, p. 50-55, 2006.

SIBILIA, Paula. O show do eu: a intimidade como espetáculo. Rio de Janeiro: Nova Fronteira, 2008.

SILVA, Tadeu Tomaz. Documentos de identidade: uma introdução às teorias do currículo. 3 ed. Belo Horizonte: Autêntica, 2011.

SMITH, Lauren Reichart; SANDERSON, Jimmy. I'm going to Instagram it! An analysis of athlete self-presentation on Instagram. Journal of Broadcasting \& Eletronic Media, v. 59, n. 2, p. 342-358, May 2015.

TROUNG, Alice. This report shows why brands should embrace Instagram (if they haven't already): a newly released report considers the photo app the best media acquisition of the last five years. 2014. Disponível em: https://www.fastcompany. com/3026419/this-report-shows-why-brands-should-embrace-instagram-if-the-haventalready. Acesso em: 12 Jul. 2020.

WACQUANT, Loïc. Corpo e alma: notas etnográficas de um aprendiz de boxe. Rio de Janeiro: Relume Dumará, 2002. 
Abstract: We aimed to analyze the self-presentation of female MMA fighters on Instagram. Images posted by female champions of the Ultimate Fighting Championship (UFC) were analyzed, considering the media representation of the image of female athlete and the objectification and the hypersexualization of their bodies. We used a coding scheme with categories for image analysis based on Goffman's studies. We found that Instagram was used for the typical social media purpose (sharing personal information and social interaction), but the UFC brand appears frequently on images posted by all fighters. In general, the images analyzed do not tend - differently from sports media coverage - to sexualize the bodies of female athletes. The images that refer to this representation were observed in the specific contexts that involve the UFC organization. The analyzed images show a plural femininity.

Keywords: Combat Sports. Gender Studies. Social Networking.

Resumen: Nuestro objetivo fue analizar la autopresentación corporal de luchadoras de MMA en Instagram. Se analizaron imágenes publicadas por luchadoras campeonas del Ultimate Fighting Championship (UFC), considerando la representación mediática de la imagen de la mujer atleta, la objetificación y la hipersexualización de sus cuerpos. Con este fin, utilizamos un esquema de codificación con categorías para el análisis de imágenes basado en los estudios de Goffman. Constatamos que Instagram fue utilizado con la finalidad típica de las redes sociales (compartir información personal e interacción social), pero la marca UFC aparece con frecuencia en las imágenes publicadas por todas las luchadoras. En general, las imágenes analizadas no presentan la tendencia, persistente en la cobertura de los medios deportivos, de sexualización del cuerpo de las mujeres atletas. Las imágenes que remiten a esa representación fueron observadas en los contextos específicos que involucran a la organización UFC. Las imágenes analizadas muestran una feminidad plural.

Palabras clave: Deportes de Combate. Estudios de Género. Red Social. 


\section{LICENÇA DE USO}

Este é um artigo publicado em acesso aberto (Open Access) sob a licença Creative Commons Atribuição 4.0 Internacional (CC BY 4.0), que permite uso, distribuição e reprodução em qualquer meio, desde que o trabalho original seja corretamente citado. Mais informações em: http://creativecommons.org/licenses/by/4.0

\section{CONFLITO DE INTERESSES}

Os autores declararam que não existe nenhum conflito de interesses neste trabalho.

\section{CONTRIBUIÇÕES AUTORAIS}

João Paulo Silva de Oliveira: Participou nas discussões para desenvolvimento da pesquisa; coleta dos dados; análise e discussão dos dados; produção do texto.

Christiane Garcia Macedo: Participou como coorientadora nas discussões para desenvolvimento da pesquisa; coleta dos dados; contribuiu na produção e revisão do texto.

Alvaro Rego Millen Neto: Participou como orientador nas discussões para desenvolvimento da pesquisa; coleta dos dados; contribuiu na produção e revisão do texto.

\section{FINANCIAMENTO}

O presente trabalho foi realizado sem qualquer apoio financeiro.

\section{ÉTICA DE PESQUISA}

O projeto de pesquisa foi encaminhado e aprovado pelo Comitê de Ética e está registrado no Sistema CEP/CONEP sob o número 80620317.8.0000.5196.

\section{COMO REFERENCIAR}

OLIVEIRA, João Paulo Silva de; MACEDO, Christiane Garcia; MILLEN NETO, Alvaro Rego. Autoapresentação corporal de lutadoras de artes marciais mistas (MMA) no Instagram. Movimento (Porto Alegre), v.27, p. e27019, jan./dez. 2021. Disponível em: https://seer.ufrgs.br/Movimento/article/view/105338. Acesso em: [dia] [mês abreviado]. [ano]. DOI: https://doi.org/10.22456/1982-8918.105338

\section{RESPONSABILIDADE EDITORIAL}

Alex Branco Fraga*, Elisandro Schultz Wittizorecki, Ivone Job*, Mauro Myskiw*, Raquel da Silveira*

* Universidade Federal do Rio Grande do Sul, Escola de Educação Física, Fisioterapia e Dança, Porto Alegre, RS, Brasil. 